\title{
Signal transduction of the (pro)renin receptor as a novel therapeutic target for preventing end-organ damage
}

\author{
Heiko Funke-Kaiser, Frank S Zollmann, Jan H Schefe and Thomas Unger
}

The (pro)renin receptor ( $(P) R R)$ not only represents a novel component of the renin-angiotensin system but is also a promising novel drug target because of its crucial involvement in the pathogenesis of renal and cardiac end-organ damage. This review discusses the signal transduction of the (P)RR with its adapter protein promyelocytic zinc-finger protein, the impact of this receptor, especially on cardiovascular disease, and its putative interaction with renin inhibitors such as aliskiren. Furthermore, the increasing complexity regarding the cellular function of the (P)RR is addressed, which arises by the intimate link with proton pumps and the phosphatase PRL-1, as well as by the presence of different subcellular localizations and of a soluble isoform of the (P)RR. Finally, the rationale and strategy for the development of small-molecule antagonists of the (P)RR, called renin/ prorenin receptor blockers, are presented.

Hypertension Research (2010) 33, 98-104; doi:10.1038/hr.2009.206; published online 11 December 2009

Keywords: promyelocytic zinc-finger protein; (pro)renin receptor; renin-angiotensin system; renin/prorenin receptor blockers; signal transduction

\section{INTRODUCTION}

Renin and prorenin are classically thought of as (pro)enzymes, but recent evidence suggests that they also can act as hormones because of their ability to bind cellular targets. ${ }^{1} \mathrm{~A}$ human (pro)renin receptor ((P)RR) -also termed renin/prorenin receptor (RER) which can specifically bind prorenin and renin, has been cloned, consisting of 350 amino acids with a single transmembrane domain. ${ }^{2}$ Interestingly, this receptor-which is expressed in organs such as the brain, heart, kidney, liver and pancreas ${ }^{2,3}$ - was reported to exert a dual function: ${ }^{2,3}$

(1) Binding of renin to this receptor increases the catalytic activity of renin by about four- to fivefold. Furthermore, prorenin, which does not exhibit significant ability to generate angiotensin I (ang I) in solution, gains enzyme activity comparable to that of renin by binding to the $(\mathrm{P}) \mathrm{RR}$, that is, the receptor is able to unmask the catalytic activity of prorenin.

(2) The (P)RR is also able to induce a signal-transduction cascade upon ligand binding. Binding of renin and also prorenin causes a phosphorylation of the receptor and a modest activation of the MAP (mitogen-activated protein) kinases (MAPKs), ERK1 and ERK2, whereas intracellular calcium or cAMP levels are not altered.

\section{SIGNAL TRANSDUCTION OF THE (P)RR}

As no direct protein interaction partner was described in the initial characterization of $(\mathrm{P}) \mathrm{RR}^{2}$ and because protein-protein interactions are crucial in understanding the mechanisms of a signal transduction cascade, our group analyzed protein-protein and downstream protein-DNA interactions of the (P)RR. Initially, we found an intracellular and ubiquitous expression pattern of the human (P)RR. ${ }^{4}$ Consistent with the latter and with housekeeping gene properties, we observed several transcriptional start sites within the TATA box-less human (P)RR promoter and a high promoter activity in different cell types. ${ }^{4}$

By yeast two-hybrid screening and co-immunoprecipitation, we identified promyelocytic zinc-finger (PLZF) protein as a direct protein interaction partner of the C-terminal domain of the $(\mathrm{P}) \mathrm{RR}$. PLZF is a zinc-finger transcription factor that is disrupted in patients with translocation $\mathrm{t}(11 ; 17)(\mathrm{q} 23 ; \mathrm{q} 21)$-associated acute promyelocytic leukemia. $^{5}$

Co-immunoprecipitation experiments also indicated homodimerization of the (P)RR. ${ }^{4}$ On activation of the (P)RR by renin, PLZF is translocated into the nucleus and represses transcription of the $(P) R R$ itself, thereby creating a very short negative feedback loop, but activates transcription of the p $85 \alpha$ subunit of the phosphatidylinositol-3 kinase (PI3K-p85 $\alpha$ ) (Figure 1). Short-interfering RNA (siRNA) 


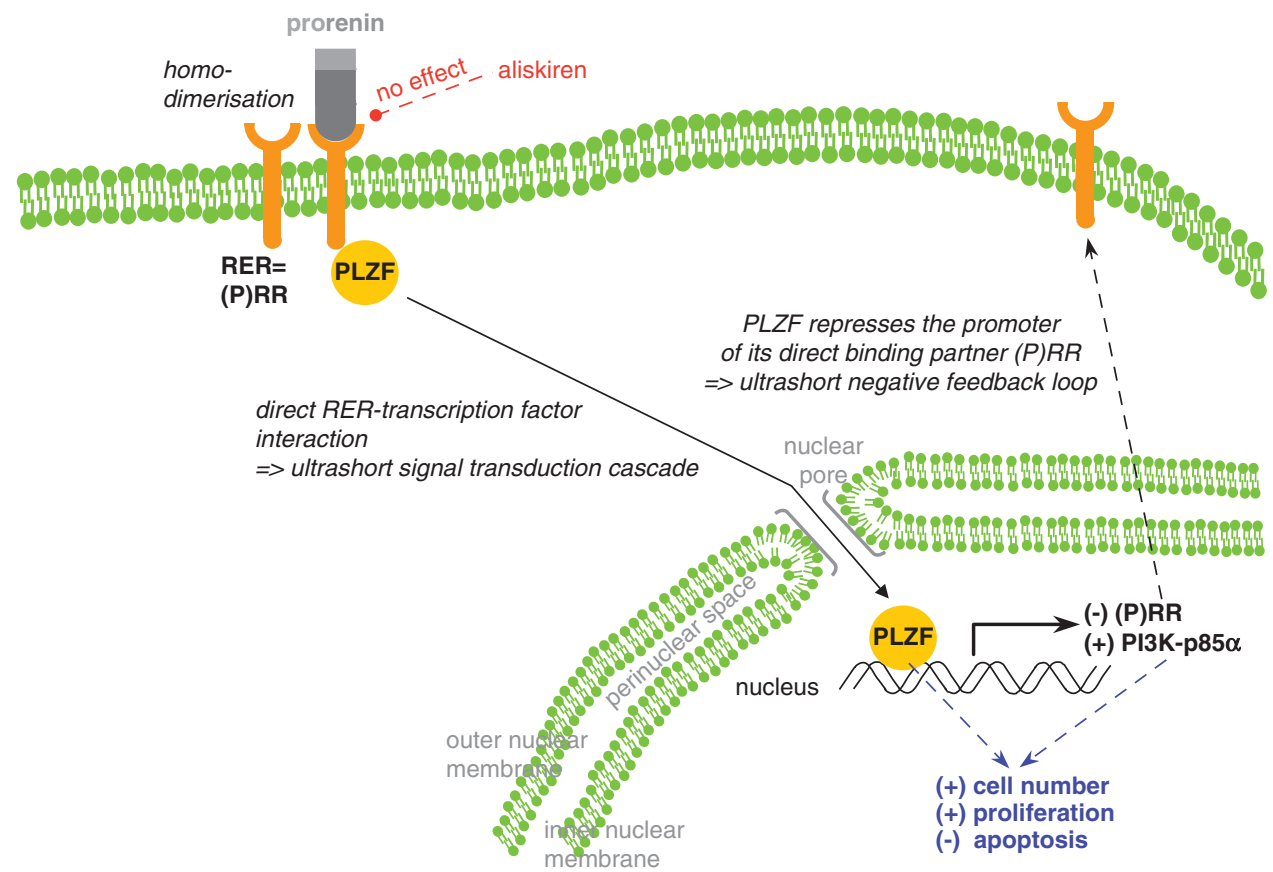

Figure 1 Signal transduction of the (P)RR based on protein-protein and protein-DNA interactions.

against the (P)RR abolished these effects. A PLZF cis-element in the $(\mathrm{P}) \mathrm{RR}$ promoter was identified by site-directed mutagenesis and electromobility shift assay. In addition, renin stimulation caused a sixfold recruitment of PLZF to this promoter region, as shown by chromatin-immunoprecipitation. ${ }^{4}$ Moreover, renin stimulation of rat $\mathrm{H} 9 \mathrm{c} 2$ cardiomyoblasts induced an increase in cell number and a decrease in apoptosis. These effects were partly abolished by PI3K inhibition and completely abrogated by siRNA against PLZF. ${ }^{4}$ Consistently, PI3K-p85 $\alpha$ and PLZF are known to be involved in stimulation of protein synthesis and cardiac hypertrophy. ${ }^{6,7}$ Finally, experiments in PLZF knockout mice confirmed the role of PLZF as an upstream regulator of (P)RR and PI3K-p85 $\alpha^{4}{ }^{4}$

Recently, we demonstrated that, besides renin, prorenin also induces the (P)RR-PLZF-PI3K-p85 $\alpha$ pathway ${ }^{8}$ (Figure 1). Furthermore, prorenin exerts proproliferative and antiapoptotic effects to a similar extent as renin, which are fully mediated by (P)RR and PLZF, as shown by siRNA experiments. Remarkably, the novel renin inhibitor (RI) aliskiren does not interfere with the intrinsic activity, that is, the noncatalytic effects, of both renin and prorenin. ${ }^{8}$

These data demonstrate the existence of a novel signal transduction pathway involving the ligands renin or prorenin the $(\mathrm{P}) \mathrm{RR}$ and the transcription factor PLZF, which is involved in cellular proliferation and apoptosis (Figure 1).

Besides the recruitment of PLZF, other groups observed the activation of MAPKs downstream of the (P)RR. ${ }^{2,9}$ This MAPK activation after stimulation of the $(\mathrm{P}) \mathrm{RR}$ with renin occurs relatively late, with a maximum described after $30 \mathrm{~min},{ }^{2}$ compared with ang II stimulation experiments that peak at about 5 min. ${ }^{10}$ In addition, Akt kinase, which itself is located downstream of PI3K, can activate MAP kinases by mechanisms involving, for example, protein kinase $\mathrm{C}$ and nitric oxide $^{11,12}$ (Figure 2). Therefore, we speculate that PLZF acts upstream of MAP kinases (Figure 2), which is supported by a recent publication that reports that expression of PLZF can enhance the activity of ERK kinase. ${ }^{13}$ Nevertheless, further experiments involving, for example, tandem affinity purification, chromatin-immunoprecipitation and siRNA are necessary to address the putative link between PLZF and MAPK. Very recently, it was demonstrated that both renin and prorenin can induce MAPKs in renal MDCK cells in the presence of ang AT1 receptor (AT1R) and ang AT2 receptor blockade. ${ }^{14}$ Nevertheless, these effects were only marginally affected by siRNA against the $(\mathrm{P}) \mathrm{RR}$, implicating other receptors in the regulation of MAPKs by (pro)renin.

Consistent with our in vitro results, the downregulation of $(\mathrm{P}) \mathrm{RR}$ mRNA by high levels of renin was also observed by other groups in certain animal models. In healthy normotensive rats, treatment with a vasopeptidase inhibitor decreased blood pressure (BP), increased renal renin mRNA and decreased (P)RR mRNA to about $80 \% .{ }^{15}$ Furthermore, administration of an angiotensin-converting enzyme (ACE) inhibitor, in addition to a low-salt diet, increased renin mRNA and protein but decreased renal (P)RR mRNA, as expected from our in vitro results. ${ }^{16}$ Consistently, inhibition of prorenin binding to the (P)RR by the use of the handle region peptide, which itself is discussed below, increased retinal (P)RR mRNA. ${ }^{17}$

In contrast, in the Goldblatt two kidney-one clip model, BP reduction increased plasma prorenin, plasma renin and renal renin mRNA expression, and also caused a parallel increase in (P)RR mRNA expression in the clipped kidney. ${ }^{15}$

In this regulatory context, it is of interest to note that diabetic rats exhibit an approximately twofold increase in renal (P)RR expression on mRNA and protein levels compared with normal rats. ${ }^{18}$ Interestingly, valsartan prevented this increase by interfering with the AT1R and the downstream NADPH oxidase. ${ }^{18}$

\section{BIOMEDICAL RELEVANCE OF THE (P)RR}

\section{Developmental biology}

It has already been shown in 2005 that a monogenic defect in the gene encoding the $(\mathrm{P}) \mathrm{RR}$ can be the cause for X-linked mental retardation associated with epilepsy in humans. ${ }^{9}$ Consistent with this observation, 


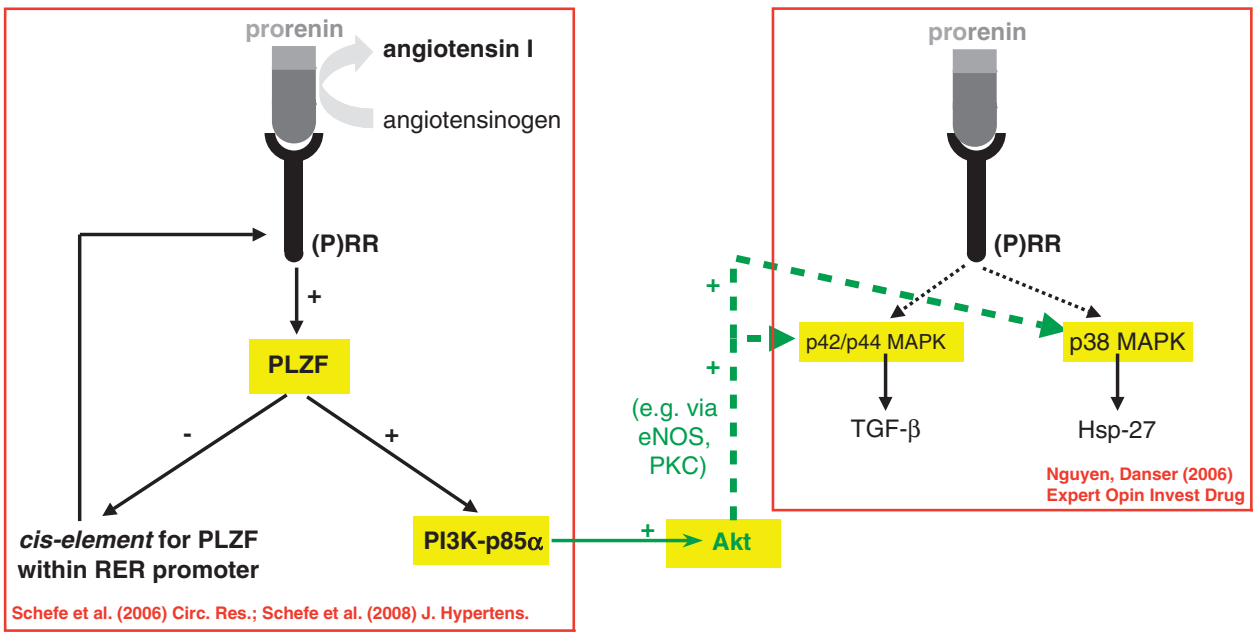

Figure 2 Signal transduction of the (P)RR—putative link between PLZF and MAPK.

the gene encoding (P)RR has a crucial role in zebrafish brain development. ${ }^{19}$ In addition, the (P)RR seems essential for early murine embryonic development, as embryonic stem cells with a mutation in the $(\mathrm{P}) \mathrm{RR}$ gene are incompatible with the development of chimeric mice when injected into blastocysts. ${ }^{20}$ Therefore, the generation of $(\mathrm{P}) \mathrm{RR}$ knockout mice has not been possible so far.

\section{Cardiovascular diseases}

Cardiac, renal and ophthalmological end-organ damage due to hypertension and/or diabetes is currently one of the major medical challenges. ${ }^{21,22}$ They contribute to approximately $60-80 \%$ of all heart failure ${ }^{23,24}$ and to $70 \%$ of renal failure ${ }^{25,26}$ cases. In addition, about $30 \%$ of blindness in Western countries is caused by these diseases. ${ }^{27-29}$ Current therapeutic strategies, such as ACE inhibitors, ang AT1R blockers, $\beta$-adrenergic receptor antagonists or antidiabetic agents only ameliorate but do not fully prevent or abolish cardiovascular end-organ damages. ${ }^{30-32}$

The relevance of the $(\mathrm{P}) \mathrm{RR}$ to these conditions is underlined by the impressive observations of Ichihara's group, which show that a decoy peptide corresponding to the handle region of prorenin named handle region peptide, which competitively inhibits prorenin binding to its receptor, attenuated the development and progression of hypertension-induced cardiac fibrosis, ${ }^{33,34}$ and also completely inhibited the development of diabetic nephropathy in different rat models including AT1R knockout mice. ${ }^{32,35}$ Consistently, it was shown that (P)RR activation can induce transforming growth factor- $\beta 1$ in mesangial cells. ${ }^{36}$ Furthermore, transgenic overexpression of the (P)RR in smooth muscle cells causes a BP elevation and an increase in heart rate, ${ }^{37}$ whereas an ubiquitous transgenic overexpression accounts for glomerulosclerosis and proteinuria. ${ }^{38}$ Other groups were unable to confirm the effects of the decoy peptide in vitro or in vivo; ${ }^{39-41}$ however, questions on handle region peptide degradation and bioavailability have not been addressed in greater detail in these publications. Another recently proposed hypothesis to explain the discrepancies with respect to the beneficial effects of the proreninderived decoys implicates the renin level, as the decoys were only effective in low-renin and not in high-renin animal models. ${ }^{42-44}$ In this context, it is important to note that the decoys competitively inhibit not only the binding of prorenin but, unexpectedly, also of renin to the $(\mathrm{P}) \mathrm{RR}^{45}$
In favor of Ichihara's handle region peptide, an independent group recently demonstrated that the decoy peptide reduced left ventricular mass index, proteinuria and creatinine in salt-overloaded spontaneously hypertensive rats. ${ }^{46}$ Furthermore, the (P)RR blocking decoy peptide was shown to abolish the renin effect on the action potential frequency in neuronal cells in vitro. ${ }^{47}$ Finally, ischemia-initiated retinal neovascularization, ${ }^{48}$ as well as diabetes-induced retinal inflammation, ${ }^{49}$ can be reduced significantly by prorenin-derived decoys.

Regarding the $(\mathrm{P}) \mathrm{RR}$ ligand prorenin, a plethora of publications have addressed its effect on the development of end-organ damage in transgenic animal models. Liver-targeted overexpression of rat prorenin caused severe renal damage (for example, glomerulosclerosis) and myocardial hypertrophy in the absence of hypertension and without an alteration in plasma renin activity compared with nontransgenic rats. ${ }^{50}$ In contrast, an inducible, transgenic, hepatic prorenin overexpression using indole-3-carbinol was associated with hypertension, moderate renal vasculopathy and moderate cardiac hypertrophy, but not with cardiac fibrosis and glomerulosclerosis, ${ }^{51,52}$ whereas a similar transgenic experiment observed glomerular damage $^{53}$ A recent, sophisticated approach used transgenic mice expressing site-mutated prorenin eliminating its enzymatic activity. ${ }^{54}$ These animals did not exhibit cardiac fibrosis or renal glomerular sclerosis. Consistently, a further transgenic model with a high-plasma wild-type prorenin level showed only modest renal lesions and myocardial fibrosis at 6 months. ${ }^{55}$ In double-transgenic mice overexpressing prorenin and angiotensinogen, end-organ damage was not analyzed in greater detail, but major abnormalities in heart or kidney using routine histological staining were not reported. ${ }^{56}$

Despite these controversies and complexities of animal models, plasma prorenin levels are predictors of the consecutive development of diabetic nephropathy and retinopathy in the human species. ${ }^{57,58}$

\section{Pharmacology-RIs}

The $(\mathrm{P}) \mathrm{RR}$ has gained increasing interest in the pharmaceutical industry because of the development of RIs with oral activity, such as Ro 66-1132 (Hoffmann-La Roche, Basel, Switzerland) or Aliskiren (CGP 60536B, SPP-100; Novartis, Basel, Switzerland). ${ }^{59-61}$ As expected, RIs reduce plasma renin activity (that is, enzyme activity with respect to ang I generation) and by this action, plasma levels of ang I and ang II as well. Nevertheless, the total amount of plasma 


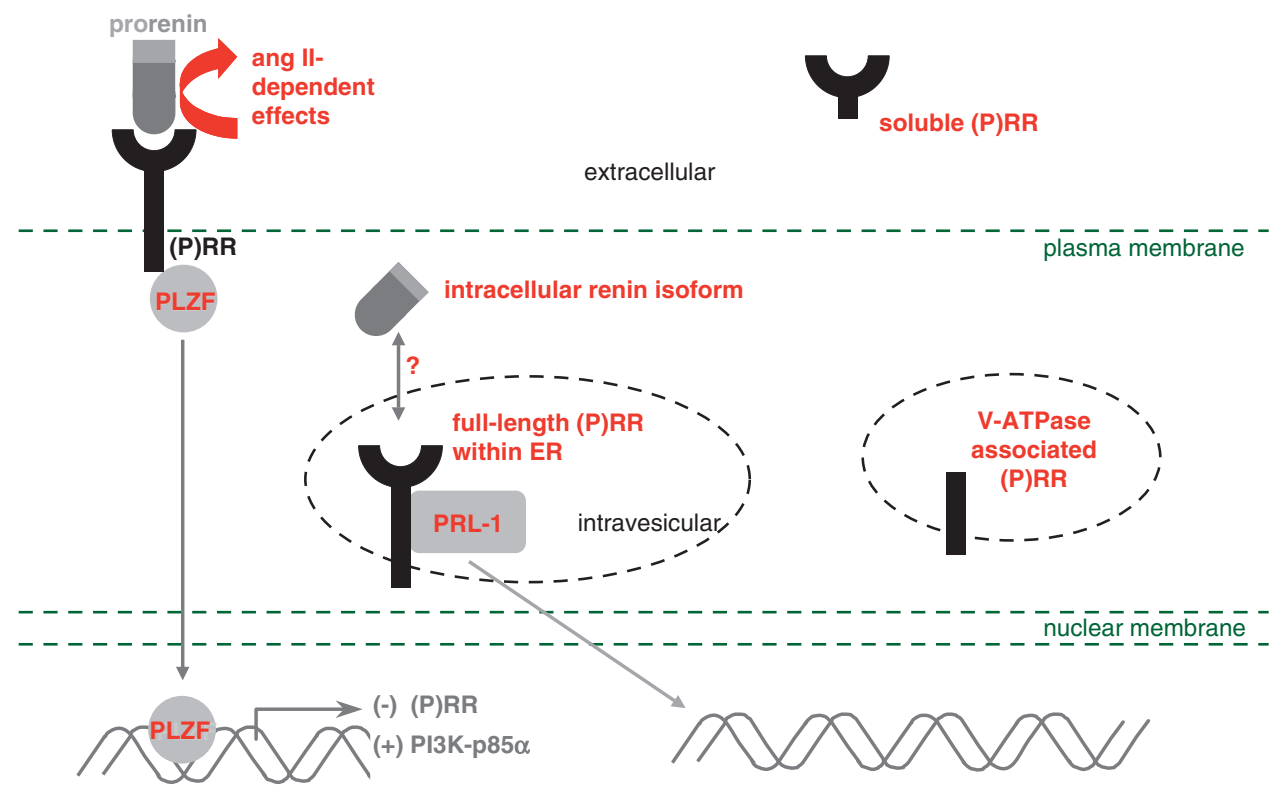

Figure 3 Increasing complexity of (P)RR-mediated cellular effects.

renin is dramatically increased on RI treatment (up to 34 -fold ${ }^{62}$ ) because the negative feedback of ang II on renin is interrupted. ${ }^{59,63,64}$ The 34-fold increase might be overestimated because of an assay artefact: by binding to prorenin, aliskiren causes a conformational change in this molecule, which is then detected as (immuno-re)active renin, that is, aliskiren allows the false detection of prorenin as renin. ${ }^{65-67}$ Nevertheless, renin inhibition can cause a greater increase in plasma renin compared with AT1R blockade at dosages with comparable antihypertensive effects. ${ }^{68}$ It has been reported that the plasma renin concentration under $300 \mathrm{mg}$ aliskiren is almost doubled compared with $320 \mathrm{mg}$ valsartan. ${ }^{43}$ In this context, studies by Laragh should be mentioned, which demonstrated that the reactive increase in renin secretion can even limit the effectiveness of aliskiren in subpopulations of patients with highly reactive renin levels, that is, the therapeutic aliskiren concentration is relatively too low to compensate for the increase in renin. ${ }^{69,70}$ In these studies reanalyzed of Laragh's group, BP did not decrease in most low-renin patients and even increased in $5 \%$ of patients taking aliskiren. In contrast, a very recent reexamination of three aliskiren trials questions the methodology used by Laragh and observed-using a different stratification cutoff-that no patient with a medium-to-high plasma renin activity at baseline had an increase in both plasma renin activity and BP. ${ }^{71}$ This implies that no treatment failure is present in this sub-population that is related to a 'disturbed stoichiometry' between increased renin and aliskiren. Nevertheless, even this study detected 'a few' patients—but not those with an increment in plasma renin activity-in whom BP increased.

Unfortunately, to our knowledge, studies directly comparing the relative effects of ACE inhibitor, ang AT1R blockers and aliskiren on plasma prorenin and renin levels in parallel-as well as the associated antihypertensive response rates-are missing. Regarding the origin of plasma renin, it is important to note that in healthy subjects and in those with essential hypertension, the prorenin plasma concentration is about ninefold higher than the renin concentration. ${ }^{72,73}$ Furthermore, at extrarenal sites-which are not subjected to the classical negative feedback loop on renin release mediated by renal AT1Rsonly prorenin is synthesized. ${ }^{74}$ These extrarenal sites contribute to $30-40 \%$ of the total plasma prorenin. ${ }^{44}$
In conclusion, it is likely that RIs will indirectly affect the activity of (P)RR in vivo. As discussed above ${ }^{8}$ and also shown by other groups, ${ }^{67,75}$ aliskiren does not inhibit the ability of renin and prorenin to induce a signal-transduction cascade at the (P)RR in vitro.

Preliminary data of our group involving 12 individuals indicate that a 3-week aliskiren therapy-compared with the pretreatment statecan decrease (in 2 of 12 cases) and also increase (in 2 of 12 cases), or does not alter (in 8 of 12 cases), the (P)RR mRNA expression in blood cells of humans in vivo. On the basis of our in vitro results ${ }^{4}$ and our expression analysis of PLZF knockout mice, ${ }^{4}$ especially the increase is unexpected. Therefore, factors such as cell type, species, in vitroin vivo transferability, signal transduction kinetics, environment, age, gender and/or genetic variabilities might affect the regulation of the (P)RR. Consistent with the latter (that is, genetic subgroups), several single nucleotide polymorphisms have been recently described in the human (P)RR gene. ${ }^{76}$ Among these, the promoter polymorphism $-782 \mathrm{~A}>\mathrm{G}$ was weakly associated with ambulatory BP. The intronic single nucleotide polymorphism $169 \mathrm{C}>\mathrm{T}$ was associated with a $24 \mathrm{~h}$ systolic BP difference of $6.4 \mathrm{mmHg}$ in men which even exceeds the effect of the well-known ACE I/D polymorphism.

\section{Oncology}

(P)RR mRNA can be detected in human glioblastomas and in glioblastoma cell lines in which RIs reduce the cell number. This reduction is probably caused by a modulation of $(\mathrm{P}) \mathrm{RR}$ function, as this effect is independent of AT1R and AT2R activity. ${ }^{77}$ The direct protein-protein interaction of the $(\mathrm{P}) \mathrm{RR}$ with the oncogenic protein phosphatase of regenerating liver-1 (PRL-1), which is discussed below, also illustrates a putative role of this receptor in oncology.

\section{INCREASING COMPLEXITY}

The (P)RR does not exhibit a homology to any other known receptor family. ${ }^{2}$ Nevertheless, the C-terminal 69-100 amino acids of the (P)RR are identical to the vacuolar proton-translocating ATPase (V-ATPase or vacuolar $\mathrm{H}^{+}$-ATPase) membrane sector-associated protein M8-9 (APT6M8-9, also known as ATP6AP2 or ATP6M8-9; GenBank 
identifier number GI:5031590) ${ }^{14,78}$ (Figure 3). V-ATPases, which are ATP-dependent proton pumps, are involved in several cellular functions such as neurotransmitter uptake and storage, endocytosis, receptor recycling and urinary acidification. ${ }^{14,79}$ The V-ATPase-associated part of the (P)RR-in contrast to the (pro)renin binding domain-is evolutionarily conserved, as it shows a high sequence homology between vertebrates (for example, mammals, fish) and invertebrates (for example, Caenorhabditis elegans and Drosophila). ${ }^{80}$ Consistently, the ligand renin is only expressed in mammalian and-as recently demonstrated in zebrafish-nonmammalian vertebrates. ${ }^{81}$ Angiotensinogen, the substrate of renin, is also expressed in zebrafish. ${ }^{82}$

It was shown by different groups that full-length $(\mathrm{P}) \mathrm{RR}$ is mainly localized intracellularly in perinuclear compartments, most likely corresponding to the endoplasmic reticulum. ${ }^{4,83}$ Interestingly, transient transfections of different (P)RR expression constructs-each Cand also N-terminally fused to EGFP-indicated that the V-ATPase segment of the $(\mathrm{P}) \mathrm{RR}$ showed a different localization pattern compared with the full-length $(\mathrm{P}) \mathrm{RR}$, as it was localized primarily to the lysosomal compartment. ${ }^{4}$ The largely intracellular location is also supported by the observation that (P)RR and CAPER (Homo sapiens endoplasmic reticulum-localized type I transmembrane adaptor precursor) are identical transcripts (GenBank accession number AY038990). CAPER was identified by yeast two-hybrid screening using the ubiquitous tyrosine phosphatase PRL-1 as bait (personal communication). The protein-protein interaction of (P)RR and PRL-1 was confirmed by co-immunoprecipitation (Schefe JH et al., unpublished data) (Figure 3). PRL-1 is involved in the regulation of cellular proliferation, transformation, as well as in tumor formation in nude mice, and exhibits a cell cycle-dependent subcellular localization. ${ }^{84,85}$ It is present in the endoplasmic reticulum in resting cells but is localized to centrosomes and to the spindle apparatus in mitotic cells. The role of PRL-1 with regard to the cellular effects of the reninangiotensin system is currently unknown.

The preferential intracellular presence of the $(\mathrm{P}) \mathrm{RR}$ contrasts with the cell surface (that is, plasma membrane) localization initially described by Nguyen et al., ${ }^{2}$ but this discrepancy might be explained by cell-type differences. Consistent with this view, preponderant (P)RR protein expression was observed at the luminal surface of rat kidney collecting duct intercalated cells. ${ }^{14}$

The coupling of (P)RR to MAP kinases and PLZF, as well as the extracellular nature of the ligands prorenin and renin, indicates that the signal transduction of this receptor is initiated at the plasma membrane, where about $10 \%$ of the (P)RR protein can be detected. ${ }^{20}$ However, other scenarios are also feasible. It has been hypothesized by Michael Bader that a further receptor for a soluble (pro)renin receptor might exist. ${ }^{80}$ This soluble form of the (P)RR termed $s(\mathrm{P}) \mathrm{RR}$ with a molecular weight of $28 \mathrm{kDa}$ was recently described in the medium of different cell types, as well as in rat and human plasma. ${ }^{86}$ Regarding its biosynthesis, the group of Nguyen confirmed the presence of fulllength $(\mathrm{P}) \mathrm{RR}$ in the endoplasmic reticulum. After trafficking to the Golgi apparatus, full-length $(\mathrm{P}) \mathrm{RR}$ is cleaved in the trans-Golgi by the action of furin generating $\mathrm{s}(\mathrm{P}) \mathrm{RR}$ and the transmembrane-cytoplasmic domain ${ }^{86,87}$ (Figure 3 ). The latter likely corresponds to the VATPase segment of the (P)RR and is retrieved in some lysosomes, whereas noncleaved (that is, furin escaped) full-length $(P) R R$ is addressed to the plasma membrane. ${ }^{86,87}$

In this context of intracellular $(\mathrm{P}) \mathrm{RRs}$, it is important to note that, besides the 'classical' preprorenin mRNA, a second mRNA isoform encoding a nonsecreted (that is, intracellular) form of active renin has been cloned in the rat, mouse and human species. This new isoform contains an alternative first exon that was termed-although

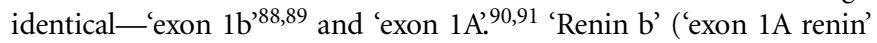
or 'exon(1A-9)renin' ${ }^{\text {'92 }}$ ) is expressed in the brain and in adrenocortical mitochondria. Remarkably, it is the only renin transcript in the heart-in contrast to the cardiac uptake of renin and prorenin proteins ${ }^{91}$ - where it is also upregulated in infarction. ${ }^{93}$ Exon $(1 \mathrm{~A}-$ 9)renin encodes a truncated, cytosolic prorenin, as it lacks the prefragment of secretory renin and the first 10 amino acids of the prosegment. ${ }^{92}$ Recently, it was shown that this cytosolic renin isoform can mediate antinecrotic but proapoptotic effects in cardiomyocytes. ${ }^{92}$ Nevertheless, a recent knockout model indicates that intracellular renin cannot functionally compensate for a loss of secreted renin. ${ }^{94}$

Despite this pathophysiological relevance, a rendezvous between this nonsecreted, cytoplasmic renin and $(\mathrm{P}) \mathrm{RR}$ is unlikely, because the (pro)renin-binding domain of the latter is localized intravesicularly, that is, not directly in the cytoplasm, or extracellularly ${ }^{80}$ (Figure 3).

\section{THE DEVELOPMENT OF RERBS}

On the basis of its crucial role in the pathophysiology of renal and cardiac end-organ damage, the $(\mathrm{P}) \mathrm{RR}$ is a promising novel therapeutic drug target for cardiovascular disease. Furthermore, cardiovascular end-organ damage represents an unmet medical need, because current therapeutic strategies, as mentioned above, only ameliorate but do not abolish this life-threatening condition. Regarding small-molecule drug development, high-throughput screening assays represent a classical first step toward exploring the chemical space for pharmacological activity. ${ }^{95}$ Therefore, the (pro)renin-(P)RR-PLZF-RER/PI3K pathway discussed above was filed as a patent (EP 1890152 A1), as it can be used as a readout for (P)RR activity within a high-throughput screening assay.

The importance of this pathway in mediating end-organ damage is also demonstrated by the observation that left ventricular hypertrophy is absent in PLZF knockout mice subjected to ang II infusion. ${ }^{96}$ Furthermore, the nuclear translocation of PLZF downstream of an AT2 receptor activation was associated with an increased protein synthesis and with growth stimulation of cardiomyocytes. ${ }^{6}$ Furthermore, PLZF is a candidate gene for obesity and insulin sensitivity, ${ }^{97}$ and an upstream regulator of the renal epithelial sodium channel. ${ }^{98}$

Supported by the GO-Bio initiative of the German Federal Ministry of Education and Research (BMBF), the aim of an interdisciplinary project team at the Center for Cardiovascular Research (CCR)/ Institute of Pharmacology of the Charite in Berlin is to develop a novel drug class called RER blockers (RERBs). RERBs will represent small molecules with oral bioavailability and the ability to inhibit the RER for the indication of hypertension- and diabetes-related renal and cardiac end-organ damage. In theory, RERBs should block both the ang II-dependent (that is, enhancement of (pro)renin's catalytic activity) and ang II-independent (that is, intrinsic activity of renin and prorenin) effects of the (P)RR.

A high-throughput screening assay based on stably transfected cell lines and a luciferase readout will be performed to screen approximately 100000 compounds of a library for inhibitory effects on the RER in cooperation with a contract research organization. To validate the putative confirmed compounds generated by this primary screening, a secondary screening based on nuclear translocation of PLZF upon (pro)renin stimulation will be used to yield the so-called hits. The methods for a subsequent hit-to-lead program to filter down these multiple hits according to pharmacodynamic, pharmacokinetic and toxicological parameters are currently being established. In addition, 
a medicinal chemistry program to optimize hits with appropriate pharmacological parameters will be run.

The in vivo proof-of-concept, which tests the effects of lead compounds with RERB activity in animal models of renal and cardiac end-organ damage, constitutes the final milestone within our BMBF GO-Bio project.

Renin/prorenin receptor blockers not only represent future drugs for human clinical trials but also experimental tools to shed light on the fascinating and complex world of the (P)RR and its adapter proteins.

\section{ACKNOWLEDGEMENTS}

The work on RER was supported by grants from the BMBF (GO-Bio program, no. 0315092), the Investitionsbank Berlin (IBB) (ProFIT program, no. 10138510) and by the Stiftung Charité.

1 Re RN. Intracellular renin and the nature of intracrine enzymes. Hypertension 2003; 42: 117-122.

2 Nguyen G, Delarue F, Burckle C, Bouzhir L, Giller T, Sraer JD. Pivotal role of the renin/prorenin receptor in angiotensin II production and cellular responses to renin. J Clin Invest 2002; 109: 1417-1427.

3 Nguyen G, Burckle CA, Sraer JD. Renin/prorenin-receptor biochemistry and functional significance. Curr Hypertens Rep 2004; 6: 129-132.

4 Schefe JH, Menk M, Reinemund J, Effertz K, Hobbs RM, Pandolfi PP, Ruiz P, Unger T, Funke-Kaiser $\mathrm{H}$. A novel signal transduction cascade involving direct physical interaction of the renin/prorenin receptor with the transcription factor promyelocytic zinc finger protein. Circ Res 2006; 99: 1355-1366.

5 Costoya JA, Pandolfi PP. The role of promyelocytic leukemia zinc finger and promyelocytic leukemia in leukemogenesis and development. Curr Opin Hematol 2001; 8 212-217.

6 Senbonmatsu T, Saito T, Landon EJ, Watanabe O, Price Jr E, Roberts RL, Imboden H, Fitzgerald TG, Gaffney FA, Inagami T. A novel angiotensin II type 2 receptor signaling pathway: possible role in cardiac hypertrophy. EMBO J 2003; 22: 6471-6482.

7 Shioi T, Kang PM, Douglas PS, Hampe J, Yballe CM, Lawitts J, Cantley LC, Izumo S. The conserved phosphoinositide 3-kinase pathway determines heart size in mice. EMBO J 2000; 19: 2537-2548.

8 Schefe JH, Neumann C, Goebel M, Danser J, Kirsch S, Gust R, Kintscher U, Unger T, Funke-Kaiser $\mathrm{H}$. Prorenin engages the (pro)renin receptor like renin and both ligand activities are unopposed by aliskiren. J Hypertens 2008; 26: 1787-1794.

9 Ramser J, Abidi FE, Burckle CA, Lenski C, Toriello H, Wen G, Lubs HA, Engert S, Stevenson RE, Meindl A, Schwartz CE, Nguyen G. A unique exonic splice enhancer mutation in a family with $\mathrm{x}$-linked mental retardation and epilepsy points to a novel role of the renin receptor. Hum Mol Genet 2005; 14: 1019-1027.

10 Otis M, Campbell S, Payet MD, Gallo-Payet N. Angiotensin II stimulates protein synthesis and inhibits proliferation in primary cultures of rat adrenal glomerulosa cells. Endocrinology 2005; 146: 633-642.

11 Yoeli-Lerner M, Toker A. Akt/pkb signaling in cancer: a function in cell motility and invasion. Cell Cycle 2006; 5: 603-605.

12 Hausenloy DJ, Yellon DM. Survival kinases in ischemic preconditioning and postconditioning. Cardiovasc Res 2006; 70: 240-253.

13 Ko JH, Son W, Bae GY, Kang JH, Oh W, Yoo OJ. A new hepatocytic isoform of plzf lacking the btb domain interacts with atp7b, the wilson disease protein, and positively regulates erk signal transduction. J Cell Biochem 2006; 99: 719-734.

14 Advani A, Kelly DJ, Cox AJ, White KE, Advani SL, Thai K, Connelly KA, Yuen D, Trogadis J, Herzenberg AM, Kuliszewski MA, Leong-Poi H, Gilbert RE. The (pro)renin receptor: site-specific and functional linkage to the vacuolar $\mathrm{h}+$-atpase in the kidney. Hypertension 2009; 54: 261-269.

15 Krebs C, Hamming I, Sadaghiani S, Steinmetz OM, Meyer-Schwesinger C, Fehr S, Stah I RA, Garrelds IM, Danser AH, van Goor H, Contrepas A, Nguyen G, Wenzel U. Antihypertensive therapy upregulates renin and (pro)renin receptor in the clipped kidney of goldblatt hypertensive rats. Kidney Int 2007; 72: 725-730.

16 Hamming I, Contrepas A, Nguyen G, Huitema S, Navis GJ, van Goor H. Regulation of the renal renin/ prorenin receptor by ACE inhibition and sodium restriction. Poster no. 22. Gordon Research Conference on Angiotensin, September 10-15, 2006, Aussois, France.

17 Wilkinson-Berka JL, Heine R, Tan G, Tikellis C, Cooper ME, Nguyen G, Miller AG. The role of the (pro)renin receptor in developing ischaemic and diabetic retina. J Renin Angiotensin Aldosterone Syst 2008; 9(Supplement 1): S8.

18 Siragy HM, Huang J. Renal (pro)renin receptor upregulation in diabetic rats through enhanced angiotensin at 1 receptor and NADPH oxidase activity. Exp Physiol 2008; 93 709-714.

19 Amsterdam A, Nissen RM, Sun Z, Swindell EC, Farrington S, Hopkins N. Identification of 315 genes essential for early zebrafish development. Proc Natl Acad Sci USA 2004; 101: 12792-12797.

20 Bader M. The (pro)renin receptor, (P)RR/ ATP6AP2, a bifunctional protein? J Renin Angiotensin Aldosterone Syst 2008; 9(Supplement 1): S5.
21 Guidelines committee. 2003 european society of hypertension-european society of cardiology guidelines for the management of arterial hypertension. J Hypertens 21; 2003: 1011-1053.

22 Cutler JA. High blood pressure and end-organ damage. J Hypertens Suppl 1996; 14: S3-S6.

23 Kannel WB. Incidence and epidemiology of heart failure. Heart Fail Rev 2000; 5: 167-173.

24 Redon J. Antihypertensive treatment: should it be titrated to blood pressure reduction or to target organ damage regression? Curr Opin Nephrol Hypertens 2005; 14: 448-452.

25 Atkins RC. The epidemiology of chronic kidney disease. Kidney Int Supp/ 2005; 94 : S14-S18.

26 Agodoa LY, Jones CA, Held PJ. End-stage renal disease in the USA: data from the united States Renal Data System. Am J Nephrol 1996; 16: 7-16.

27 Girach A, Manner D, Porta M. Diabetic microvascular complications: can patients at risk be identified? A review. Int J Clin Pract 2006; 60: 1471-1483.

28 Lightman S, Towler HM. Diabetic retinopathy. Clin Cornerstone 2003; 5: 12-21.

29 Buch H, Vinding T, Nielsen NV. Prevalence and causes of visual impairment according to World Health Organization and United States criteria in an aged, urban Scandinavian population: the Copenhagen City Eye Study. Ophthalmology 2001; 108: 2347-2357.

30 Banerjee D, Materson BJ. Blood pressure-independent impact of antihypertensive agents on cardiovascular and renal disease. Curr Hypertens Rep 2002; 4: 445-452.

31 Sleight P. Angiotensin II and trials of Cardiovascular Outcomes. Am J Cardiol 2002; 89. 11A-16A; discussion 16A-17A.

32 Ichihara A, Suzuki F, Nakagawa T, Kaneshiro Y, Takemitsu T, Sakoda M, Nabi AH, Nishiyama A, Sugaya T, Hayashi M, Inagami T. Prorenin receptor blockade inhibits development of glomerulosclerosis in diabetic angiotensin II type 1a receptor-deficient mice. J Am Soc Nephrol 2006; 17: 1950-1961.

33 Ichihara A, Kaneshiro $Y$, Takemitsu T, Suzuki F, Nakagawa $T$, Nishiyama A, Iwata $H$, Ishida Y, Inagami T, Saruta T, Hayashi M. 'Receptor-associated prorenin system' contributes to hypertensive end-organ damage. J Hypertens 2005; 23 (suppl 2): S78, P1.197.

34 Ichihara A, Kaneshiro Y, Takemitsu T, Sakoda M, Suzuki F, Nakagawa T, Nishiyama A, Inagami T, Hayashi M. Nonproteolytic activation of prorenin contributes to development of cardiac fibrosis in genetic hypertension. Hypertension 2006; 47: 894-900.

35 Ichihara A, Hayashi M, Kaneshiro Y, Suzuki F, Nakagawa T, Tada Y, Koura Y, Nishiyama A, Okada H, Uddin MN, Nabi AH, Ishida Y, Inagami T, Saruta T. Inhibition of diabetic nephropathy by a decoy peptide corresponding to the 'handle' region for nonproteolytic activation of prorenin. J Clin Invest 2004; 114: 1128-1135.

36 Huang Y, Wongamorntham S, Kasting J, McQuillan D, Owens RT, Yu L, Noble NA, Border W. Renin increases mesangial cell transforming growth factor-betal and matrix proteins through receptor-mediated, angiotensin II-independent mechanisms. Kidney Int 2006; 69: 105-113.

37 Burckle CA, Jan Danser AH, Muller DN, Garrelds IM, Gasc JM, Popova E, Plehm R, Peters J, Bader M, Nguyen G. Elevated blood pressure and heart rate in human renin receptor transgenic rats. Hypertension 2006; 47: 552-556.

38 Kaneshiro Y, Ichihara A, Sakoda M, Takemitsu T, Nabi AH, Uddin MN, Nakagawa T, Nishiyama A, Suzuki F, Inagami T, Itoh H. Slowly progressive, angiotensin II-independent glomerulosclerosis in human (pro)renin receptor-transgenic rats. J Am Soc Nephrol 2007; 18: 1789-1795.

39 Feldt S, Batenburg WW, Mazak I, Maschke U, Wellner M, Kvakan H, Dechend R, Fiebeler A, Burckle C, Contrepas A, Jan Danser AH, Bader M, Nguyen G, Luft FC, Muller DN. Prorenin and renin-induced extracellular signal-regulated kinase 1/2 activation in monocytes is not blocked by aliskiren or the handle-region peptide. Hypertension 2008; 51: 682-688.

40 Batenburg WW, Krop M, Garrelds IM, de Vries R, de Bruin RJ, Burckle CA, Muller DN, Bader M, Nguyen G, Danser AH. Prorenin is the endogenous agonist of the (pro)renin receptor. Binding kinetics of renin and prorenin in rat vascular smooth muscle cells overexpressing the human (pro)renin receptor. J Hypertens 2007; 25: 2441-2453.

41 Muller DN, Klanke B, Feldt S, Cordasic N, Hartner A, Schmieder RE, Luft FC, Hilgers KF. pro)renin receptor peptide inhibitor "handle-region" peptide does not affect hypertensive nephrosclerosis in Goldblatt rats. Hypertension 2008; 51: $676-681$.

42 Ichihara A, Sakoda M, Kurauchi-Mito A, Narita T, Kinouchi K, Itoh H. Drug discovery for overcoming chronic kidney disease (CKD): new therapy for CKD by a (pro)reninreceptor-blocking decoy peptide. J Pharmacol Sci 2009; 109: 20-23.

43 Danser AJ, Nguyen G. The Renin academy summit: advancing the understanding of renin science. J Renin Angiotensin Aldosterone Syst 2008; 9: 119-123.

44 Danser AHJ. Prorenin, the (Pro)renin Receptor, and Renin Inhibition. Chapter 4, pp 1-20 In: Hollenberg NK (ed), Braunwald E (Series ed). Atlas of Hypertension, 6th edn CMG (Current Medicine Group) LLC, a division of Springer Science+Business Media LLC: Philadelphia, 2009. pp 19106-192352.

45 Nabi AH, Biswas KB, Nakagawa T, Ichihara A, Inagami T, Suzuki F. Decoy peptide region (riflkrmpsi) of prorenin prosegment plays a crucial role in prorenin binding to the (pro)renin receptor. Int J Mol Med 2009; 24: 83-89.

46 Susic D, Zhou X, Frohlich ED, Lippton H, Knight M. Cardiovascular effects of prorenin blockade in genetically spontaneously hypertensive rats on normal and high-salt diet. Am J Physiol Heart Circ Physiol 2008; 295: H1117-H1121.

47 Shan Z, Cuadra AE, Sumners C, Raizada MK. Characterization of a functional (pro)renin receptor in rat brain neurons. Exp Physiol 2008; 93: 701-708.

48 Satofuka S, Ichihara A, Nagai N, Koto T, Shinoda H, Noda K, Ozawa Y, Inoue M, Tsubota K, Itoh H, Oike Y, Ishida S. Role of nonproteolytically activated prorenin in 
pathologic, but not physiologic, retinal neovascularization. Invest Ophthalmol Vis Sci 2007; 48: 422-429.

49 Satofuka S, Ichihara A, Nagai N, Noda K, Ozawa Y, Fukamizu A, Tsubota K, Itoh H, Oike $\mathrm{Y}$, Ishida $\mathrm{S}$. (Pro)renin receptor-mediated signal transduction and tissue renin-angiotensin system contribute to diabetes-induced retinal inflammation. Diabetes 2009; 58: 1625-1633.

50 Veniant M, Menard J, Bruneval P, Morley S, Gonzales MF, Mullins J. Vascular damage without hypertension in transgenic rats expressing prorenin exclusively in the liver. J Clin Invest 1996; 98: 1966-1970.

51 Peters B, Grisk O, Becher B, Wanka H, Kuttler B, Ludemann J, Lorenz G, Rettig R, Mullins JJ, Peters J. Dose-dependent titration of prorenin and blood pressure in Cypla1ren-2 transgenic rats: absence of prorenin-induced glomerulosclerosis. J Hypertens 2008; 26: 102-109.

52 Peters J, Schluter T, Riegel T, Peters BS, Beineke A, Maschke U, Hosten N, Mullins JJ, Rettig R. Lack of cardiac fibrosis in a new model of high prorenin hyperaldosteronism. Am J Physiol Heart Circ Physiol 2009; 297: H1845-H1852.

53 Graciano ML, Mouton CR, Patterson ME, Seth DM, Mullins JJ, Mitchell KD. Renal vascular and tubulointerstitial inflammation and proliferation in Cyp1a1-Ren2 transgenic rats with inducible ang ii-dependent malignant hypertension. Am J Physiol Renal Physiol 2007; 292: F1858-F1866.

54 Mercure C, Prescott G, Lacombe MJ, Silversides DW, Reudelhuber TL. Chronic increases in circulating prorenin are not associated with renal or cardiac pathologies. Hypertension 2009; 53: 1062-1069.

55 Campbell DJ, Karam H, Menard J, Bruneval P, Mullins JJ. Prorenin contributes to angiotensin peptide formation in transgenic rats with rat prorenin expression targeted to the liver. Hypertension 2009; 54: 1248-1253.

56 Prescott G, Silversides DW, Reudelhuber TL. Tissue activity of circulating prorenin. Am J Hypertens 2002; 15: 280-285.

57 Luetscher JA, Kraemer FB, Wilson DM, Schwartz HC, Bryer-Ash M. Increased plasma inactive renin in diabetes mellitus. A marker of microvascular complications. N Engl J Med 1985; 312: 1412-1417.

58 Wilson DM, Luetscher JA. Plasma prorenin activity and complications in children with insulin-dependent diabetes mellitus. N Eng/ J Med 1990; 323: 1101-1106.

59 Maibaum J, Feldman DL. Renin inhibitors as novel treatments for cardiovascular disease. Expert Opin Ther Patents 2003; 13: 589-603.

60 Stanton A, Jensen C, Nussberger J, O'Brien E. Blood pressure lowering in essential hypertension with an oral renin inhibitor, aliskiren. Hypertension 2003; 42: 1137-1143.

61 Hershey JC, Steiner B, Fischli W, Feuerstein G. Renin inhibitors: an antihypertensive strategy on the vergeof reality. Drug Discov Today: Therapeutic Strategies 2005; 2: $181-185$.

62 Nussberger J, Wuerzner G, Jensen C, Brunner HR. Angiotensin II suppression in humans by the orally active renin inhibitor aliskiren (spp100): comparison with enalapril. Hypertension 2002; 39: e1-e8.

63 Verburg KM, Kleinert HD, Kadam JR, Chekal MA, Mento PF, Wilkes BM. Effects of chronic infusion of renin inhibitor A-64662 in sodium-depleted monkeys. Hypertension 1989; 13: 262-272.

64 Boger RS, Glassman HN, Cavanaugh JH, Schmitz PJ, Lamm J, Moyse D, Cohen A, Kleinert HD, Luther RR. Prolonged duration of blood pressure response to enalkiren, the novel dipeptide renin inhibitor, in essential hypertension. Hypertension 1990; 15: $835-840$.

65 Campbell DJ. Interpretation of plasma renin concentration in patients receiving aliskirentherapy. Hypertension 2008; 51: 15-18.

66 Menard J, Azizi M. The difficult conception, birth and delivery of a renin inhibitor: controversies around aliskiren. J Hypertens 2007; 25: 1775-1782.

67 Batenburg WW, de Bruin RJ, van Gool JM, Muller DN, Bader M, Nguyen G, Danser AH. Aliskiren-binding increases the half life of renin and prorenin in rat aortic vascular smooth muscle cells. Arterioscler Thromb Vasc Biol 2008; 28: 1151-1157.

68 Azizi M, Menard J, Bissery A, Guyenne TT, Bura-Riviere A, Vaidyanathan S, Camisasca RP. Pharmacologic demonstration of the synergistic effects of a combination of the renin inhibitor aliskiren and the at1 receptor antagonist valsartan on the angiotensin IIrenin feedback interruption. J Am Soc Nephrol 2004; 15: 3126-3133.

69 Sealey JE, Laragh JH. Aliskiren, the first renin inhibitor for treating hypertension: reactive renin secretion may limit its effectiveness. Am J Hypertens 2007; 20: 587-597.

70 Sealey JE, Laragh JH. Aliskiren fails to lower blood pressure in patients who have either low pra levels or whose pra falls insufficiently or reactively rises. Am J Hypertens 2009; 22: 112-121.

71 Stanton AV, Dicker P, O'Brien ET. Aliskiren monotherapy results in the greatest and the least blood pressure lowering in patients with high- and low-baseline pra levels, respectively. Am J Hypertens 2009; 22: 954-957.

72 Schalekamp MA, Derkx FH, Deinum J, Danser AJ. Newly developed renin and prorenin assays and the clinical evaluation of renin inhibitors. J Hypertens 2008; 26: 928-937.

73 Nguyen G. Renin/prorenin receptors. Kidney Int 2006; 69: 1503-1506.
74 Campbell DJ. Critical review of prorenin and (pro)renin receptor research. Hypertension 2008; 51: 1259-1264.

75 Feldt S, Maschke U, Dechend R, Luft FC, Muller DN. The putative (pro)renin receptor blocker hrp fails to prevent (pro)renin signaling. J Am Soc Nephrol 2008; 19: 743-748.

76 Hirose T, Hashimoto M, Totsune K, Metoki H, Asayama K, Kikuya M, Sugimoto K, Katsuya T, Ohkubo T, Hashimoto J, Rakugi H, Takahashi K, Imai Y. Association of (pro)renin receptor gene polymorphism with blood pressure in Japanese men: the Ohasama study. Am J Hypertens 2009; 22: 294-299.

77 Juillerat-Jeanneret L, Celerier J, Chapuis Bernasconi C, Nguyen G, Wostl W, Maerki HP, Janzer RC, Corvol P, Gasc JM. Renin and angiotensinogen expression and functions in growth and apoptosis of human glioblastoma. Br J Cancer 2004; 90 : 1059-1068.

78 Ludwig J, Kerscher S, Brandt U, Pfeiffer K, Getlawi F, Apps DK, Schagger H. Identification and characterization of a novel 9.2-kDa membrane sector-associated protein of vacuolar proton-atpase from chromaffin granules. J Biol Chem 1998; 273: 10939-10947.

79 Nelson N, Harvey WR. Vacuolar and plasma membrane proton-adenosinetriphosphatases. Physiol Rev 1999; 79: 361-385.

80 Bader M. The second life of the (pro)renin receptor. J Renin Angiotensin Aldosterone Syst 2007; 8: 205-208.

81 Liang P, Jones CA, Bisgrove BW, Song L, Glenn ST, Yost HJ, Gross KW. Genomic characterization and expression analysis of the first nonmammalian renin genes from zebrafish and pufferfish. Physiol Genomics 2004; 16: 314-322.

82 Endo Y, Chen M, Vallon V, Schnermann J, Briggs JP. Expression of cathepsin D and angiotensinogen in nephrons of zebrafish (Danio rerio) kidney. Bull Mt Desert Island Biol Lab 2000; 38: 31-32.

83 Saris JJ, t Hoen PA, Garrelds IM, Dekkers DH, den Dunnen JT, Lamers JM, Jan Danser $\mathrm{AH}$. Prorenin induces intracellular signaling in cardiomyocytes independently of angiotensin II. Hypertension 2006; 48: 564-571.

84 Cates CA, Michael RL, Stayrook KR, Harvey KA, Burke YD, Randall SK, Crowell PL, Crowell DN. Prenylation of oncogenic human ptp(caax) protein tyrosine phosphatases. Cancer Lett 1996; 110: 49-55.

85 Wang J, Kirby CE, Herbst R. The tyrosine phosphatase prl-1 localizes to the endoplasmic reticulum and the mitotic spindle and is required for normal mitosis. $J$ Biol Chem 2002; 277: 46659-46668.

86 Cousin C, Bracquart D, Contrepas A, Corvol P, Muller L, Nguyen G. Soluble form of the (pro)renin receptor generated by intracellular cleavage by furin is secreted in plasma. Hypertension 2009; 53: 1077-1082.

87 Praizovic NG, Contrepas AN, Muller L, Corvol P, Nguyen G. Intracellular localization and processing of the (pro)renin receptor. Abstract P85, 61st Annual High Blood Pressure Research Conference. Westin La Paloma, Tuscon, AZ, September 26-29, 2007.

88 Lee-Kirsch MA, Gaudet F, Cardoso MC, Lindpaintner K. Distinct renin isoforms generated by tissue-specific transcription initiation and alternative splicing. Circ Res 1999; 84: 240-246.

89 Sinn PL, Sigmund CD. Identification of three human renin mrna isoforms from alternative tissue-specific transcriptional initiation. Physiol Genomics 2000; 3: 25-31.

90 Clausmeyer S, Sturzebecher R, Peters J. An alternative transcript of the rat renin gene can result in a truncated prorenin that is transported into adrenal mitochondria. Circ Res 1999; 84: 337-344.

91 Peters J, Clausmeyer S. Intracellular sorting of renin: cell type specific differences and their consequences. J Mol Cell Cardiol 2002; 34: 1561-1568.

92 Wanka H, Kessler N, Ellmer J, Endlich N, Peters BS, Clausmeyer S, Peters J. Cytosolic renin is targeted to mitochondria and induces apoptosis in $\mathrm{H} 9 \mathrm{c} 2$ rat cardiomyoblasts. J Cell Mol Med 2009; 13: 2926-2937.

93 Clausmeyer S, Reinecke A, Farrenkopf R, Unger T, Peters J. Tissue-specific expression of a rat renin transcript lacking the coding sequence for the prefragment and its stimulation by myocardial infarction. Endocrinology 2000; 141: 2963-2970.

94 Xu D, Borges GR, Grobe JL, Pelham CJ, Yang B, Sigmund CD. Preservation of intracellular renin expression is insufficient to compensate for genetic loss of secreted renin. Hypertension 2009; 54: 1240-1247.

95 Bleicher KH, Bohm HJ, Muller K, Alanine Al. Hit and lead generation: beyond highthroughput screening. Nat Rev Drug Discov 2003; 2: 369-378.

96 Wang N, Satonaka H, Frank GD, Wicks K, Rachakonda A, Ding R, Landon EJ, Pandolfi PP, Inagami T. Abstract 013 Annual High Blood Pressure Research Conference. Tuscon, 2007.

97 Seda O, Liska F, Sedova L, Kazdova L, Krenova D, Kren V. A 14-gene region of rat chromosome 8 in shr-derived polydactylous congenic substrain affects muscle-specific insulin resistance, dyslipidaemia and visceral adiposity. Folia Biol (Praha) 2005; 51: 53-61.

98 Naray-Fejes-Toth A, Boyd C, Fejes-Toth G. Regulation of epithelial sodium transport by promyelocytic leukemia zinc finger protein. Am J Physiol Renal Physiol 2008; 295: F18-F26. 